\title{
Polyamines Deficient Diet is a Complementary Strategy in Fighting Cancer: Analysis on Selected Medicinal Fruits
}

\author{
Radiah Abdul Ghani, Elyna Fatini Jamil, Muhammad Ibrahim
}

\begin{abstract}
Polyamines are one of the oldest substances known in biochemistry consist of putrescine, spermidine and spermine. They are essential components of all living cells primarily involve in cell growth and proliferation. Upregulation of polyamines in human body is highly associated with various diseases, including cancer. Therefore, polyamines deficient diet (PDD) has become one of the strategies to inhibit carcinogenesis. This study was aimed to determine the polyamines content in selected anticancer fruits and their effect on polyamine polyamine metabolic enzymes was explored in human lung adenocarcinoma cells (A549). In this study, the selected medicinal fruits are Phoenix dactylifera (ajwa dates),Ficus auriculata (fig),Beta vulgaris (beetroot), Ziziphus jujube (jujube) and Vitis vinifera (raisin). The selected medicinal fruits were initially grouped into classes based on total polyamines content using High performance Liquid Chromatography (HPLC). The ability of selected fruits to reduce $A 549$ intracellular polyamines was determined using the same technique. Accordingly, changes in polyamine metabolic enzymes activities; ornithine decarboxylase (ODC) and spermidine/spermine $\quad \mathrm{N}$-acetyltransferase (SSAT) were measured correspondingly using quantitative polymerase chain reactions (qPCR). Results suggested Beetroot, ajwa dates, fig and raisin are classified as low polyamines fruits while jujube demonstrates high content of polyamines. Significant decreased of total intracellular polyamine content after $24 \mathrm{~h}$ of treatments with these fruits were identified when compared with untreated A549 cells.Ornithine decarboxylase (ODC) activity showed downregulation upon treatment with ajwa dates, jujube and raisin while SSAT activity displayed alterations in beetroot and jujube treated A549 cells. Thus, we concluded that beetroot, ajwa dates, fig and raisins are the promising candidates for PDD strategy for their low polyamines, ability to reduce A549 intracellular polyamines and modification on ODC and SSAT activities.
\end{abstract}

Index Terms: Polyamine Reduce Diet; Prophetic Fruits; ODC; SSAT; Lung Cancer.

\section{INTRODUCTION}

Cancer is a major public health problem around the globe accounting for top cause of morbidity and mortality (World

Revised Manuscript Received on October 15, 2019.

Radiah Abdul Ghani, Department of Biomedical Science, Kulliyyah of Allied Health Sciences, International Islamic University Malaysia, radiah@iium.edu.my

Elyna Fatini Jamil, Department of Biomedical Science, Kulliyyah of Allied Health Sciences, International Islamic University Malaysia

Muhammad Ibrahim, Department of Nutritional Science, Kulliyyah of Allied Health Sciences, International Islamic University Malaysia.
Health Organization [WHO], 2015). Lung cancer contributes to the highest $(13 \%)$ cancer burden worldwide, followed by breast cancer $(11.9 \%)$ and colorectal cancer $(9.7 \%)$. These intensifying figures are expected to increase one fold for the next two decades (World Cancer Report, 2014). With regard to this matter, healthcare professionals and authorities are actively seeking for effective prevention strategies of one possible approach is chemoprevention. Chemoprevention employs natural or synthetic agents that are able to inhibit, suppress or reverse cancer initiation and progression (Steward and Brown, 2013). Plenty of researches have demonstrated positive outcomes in chemoprevention therapy, indicating them as a rational and appealing strategy. To support this, the consumption of medicinal plants has existed since ancient times to prevent and cure diseases including cancer (Mehta et al., 2010).

Despite pronounce health benefits they offer, natural medicines do impose risks to cancer patients and high risk population following their consumption. Milner (2008) reported thousands of compounds are estimated to present in fruits and vegetables, among one of them is polyamines. Cellular polyamine (putrescine, spermidine and spermine) is polycationic biologic amines that ubiquitously present in all eukaryotes. They derive from three sources typically from endogenous biosynthesis, intestinal microorganisms and diet (Kalač, 2009). Polyamine involves in various physiological functions varying from cell growth and proliferation to cell survival and death. The intracellular polyamine level is tightly controlled by a balance mechanism between biosynthesis, interconversion and degradation. However, it is frequently dysregulated in the case of cancer and normal physiological polyamine levels are often disturbs.

Significant association between intracellular polyamine and cancer development has been observed in various types of cancer (Babbar \& Gerner, 2011). Increase intracellular polyamine content somehow promotes unwarranted cell growth and proliferation. Since polyamine can be obtained from diet, it is essential to conduct polyamine analysis in local food in Malaysia to provide basis for polyamine deficient diet (PDD) in cancer patients and high-risk population such as cancer survivor or inherited types of cancer.

Published By: Blue Eyes Intelligence Engineering \& Sciences Publication 
Cipolla et al. (2010) confirmed the practicality of PDD therapy in metastatic hormone-refractory prostate cancer (HRPC) by improving patients' quality of life and pain control.

To the knowledge of researcher, polyamine analysis in local medicinal plants and fruits is not being elaborated. Thus, for the first time, this study aimed to determine the polyamines classification among well-known anticancer plants or fruits. To begin, a range of medicinal fruits such as Phoenix dactylifera (ajwa dates), Beta vulgaris (beetroot), Ficus auriculata (fig), Zizyphus jujube (jujube), Vitis vinifera (raisins) as recommended by Prophet Muhammad (Pbuh) were studied. Moreover, the effect of these medicinal plants on polyamine intracellular content was identified. To further understand the mechanism, the effects of these plants were determined on polyamine metabolic enzymes which are Ornithine decarboxylase (ODC) and Spermine Spermidine Acetyl Tranferase (SSAT) in human lung adenocarcinoma cells, A549.

\section{LITERATURE REVIEW}

\section{A. Cancer}

Lung cancer has been recognized as the leading cause of cancer related deaths (19\% of the total) (Zagryazhskaya and Zhivotovsky, 2014) and the most common cause of cancer in men (World Health Organization, 2012). The cancer burden is greater than three other most common cancers collectively, particularly the colorectal, breast and prostate cancer. World lung cancer statistics revealed that approximately 1.59 million deaths occur every year (World Health Organization [WHO], 2015). The majority of lung cancer cases established from unknown initiation events that trigger malignant transformation of bronchoepithelial cells (Horn et al., 2014). Development of lung cancer is usually facilitated by extrinsic components, predominantly the tobacco smokes, asbestos fibers as well as some environmental carcinogens (Zagryazhskaya and Zhivotovsky, 2014). Interaction between genome of the respiratory epithelium and environmental factors results in carcinogenesis (Sher et al., 2008). The contribution of extrinsic carcinogen on genetic transformation is modulated by genetic variations; it affects the metabolism of pro-carcinogens to carcinogens and their subsequent inactivation (Zienolddiny et al., 2006).

Current standard therapy for lung cancer is comprises of surgical resection, radiotherapy and chemotherapy. Unfortunately, these treatments are ineffective for approximately half of cancer patients (Siegel et al., 2012) owing to resistance to drugs (Huang et al., 2014), non-specific targeting of chemotherapeutic agents, and side effects from cancer treatments. Moreover, progress in lung cancer therapy has been slow irrespective of their high prevalence as a result of perception that we had hit a plateau phase where development of treatment had stopped about 10 years ago (Cancer Research UK, 2013). However, lung cancer incidences can be reduced if the risk of developing it is minimized. It takes long latency period to develop lung cancer, therefore, allowing interventions in between of lung carcinogenesis. Of this, chemoprevention appears to be the ideal solution. Keep in mind that chemoprevention is not an alternative approach to anti-cancer treatment, but a step need to be taken for all individual and high risk populations to reduce risk of acquiring lung cancer.

\section{B. Polyamines and Cancer}

Polyamines are one of the oldest groups of substances known in biochemistry consist of putrescine, spermidine and spermine. Putrescine is a naturally occurring polyamines identified more than 100 years ago in putrefying cadavers as a result of bacterial decomposition. It is responsible for the foul odor of the putrefying flesh of cadaver. The name spermidine was attributed to a previously chemically synthesized bovine pancreatic polyamine, while spermine, the three-sided looking crystals was discovered more than 300 years ago in ageing human spermatozoa (Wallace, 2009).

Based on studies performed in tissue culture, animals and human, increased intracellular polyamine levels are associated with cancer (Palmer et al., 2009). The increase of polyamines in malignant cells has attracted the interest in this area of research since last few decades, (Gerner et al., 2004). Polyamines depletion has become one of the strategies to inhibit carcinogenesis, by way of targeting each biosynthetic and catabolic steps of the polyamines metabolism (Wallace, 2009). Previous studies reported the used of alpha-difluoromethylornithine (DFMO) to prevent cancers. It was the first drug designed to cease cell proliferation by interfering with polyamine metabolism particularly the ODC activity. DFMO administration diminishes growth rate and depletes putrescine and spermidine intracellular contents on several normal and malignant cell lines. However, DFMO produces cytostatic effect rather than cytotoxic on both polyamine catabolism and cellular polyamine uptake. Despite its use against melanomas, gliomas and other solid tumors, DFMO has limited therapeutic effect since high concentration is needed to inhibit ODC as well as the poor cellular uptake (Palmer et al., 2009). Due to this reason, scientists have utilized the idea of chemoprevention to interfere with polyamine metabolism.

\section{Polyamine Deficient Diet, a Strategy for Cancer Prevention}

Food comprises of abundant bioactive compounds, beneficial to the human organism. For many years, it is believed that diet can influence various diseases, and the results are often positive (Langner and Rzeski, 2012). Several researches reported the success of polyamine deficient diet (PDD) in reducing cancer. Natural products of low polyamine content have demonstrated to interfere with polyamine metabolism by way of reducing spemidine and spermine in A549 cells (Ghani et al., 2015). Seiler showed that tumor-bearing animals fed with PDD together with

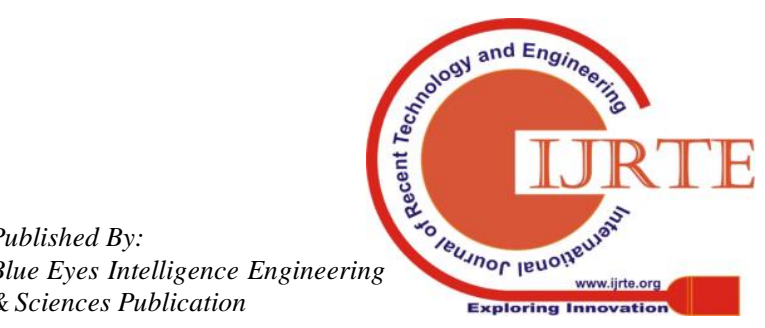


DFMO and neomycin (partial decontamination of the gastrointestinal tract) exhibited significant inhibition of tumor progression and metastasis spreading (Cipolla et al., 2007). Moreover, $40 \%$ inhibition in tumor progression and metastasis spreading was observed in tumor-grafted animals fed with PDD and neomycin only. The studies above strengthened the potential of polyamine reduced diet in chemoprevention. Many researchers have discovered positive outcome when using nutritional therapy to treat diseases. Nutritional therapy is recognized as a complementary medicine for individuals with chronic conditions, as well as to those who wants to enhance their health and wellbeing. In the present study, nutritional therapy mainly the polyamine low diet is our major interest as a cancer prevention strategy.

\section{METHODOLOGY/MATERIALS}

\section{A. Collection and species identification of samples}

Plants specimens were collected complete with stem, branches, leaves and flowers together with necessary information, including location, habitat and characteristics. $P$. dactylifera (ajwa dates), B. vulgaris (beetroot), $F$. auriculata (fig) and $V$. vinifera (raisins) were completely dried in the oven (Memmert UN55plus) at a temperature of $60{ }^{\circ} \mathrm{C}$ to $37^{\circ} \mathrm{C}$ in the decrement of $5^{\circ} \mathrm{C}$ until constant weight achieved. Dried specimens were kept in separate plastics complete with label to avoid samples mixed up. Jujube components were spread flat on sheets of newspaper and folded. The newspaper was put in autoclavable bag and sprayed with $70 \%$ ethanol just enough to wet the sample. It was kept in the dark for 3 days to sterilize and kills senescence enzyme. Completed form containing plants information was submitted and voucher specimens were deposited once they were identified. The number of voucher specimens obtained from these plants are, PIIUM 0241(P. dactylifera; ajwa date), PIIUM 0242 (B. vulgaris; beetroot), PIIUM 0240 (F. auriculata; fig), PIIUM 0253 (Z. jujube; jujube) and PIIUM 0243 (V. vinifera; raisin).

\section{B. Preparation of samples}

B. vulgaris (beetroot), F. auriculata (fig) and Z. jujube (jujube) of the fruit part were thoroughly washed with tap water and distilled water until all dirt came off. Altogether including P. dactylifera (ajwa dates) and V. vinifera (raisins) were weighted with electronic weighing balance (Mettler Toledo EL303-IC) and their weight were subsequently recorded. The fruits were homogeneously cut into small pieces and stored in ultra-low temperature freezer at $-80{ }^{\circ} \mathrm{C}$ overnight (Haier DW-86L388). On the next day, frozen samples were freeze dried with freeze drying machine (Eyela FDU-1200) for a week. The temperature and pressure were all set at $-50{ }^{\circ} \mathrm{C}$ and $8.4 \mathrm{~Pa}$ and kept in $-80^{\circ} \mathrm{C}$ until analysis.

\section{Polyamine extraction from samples}

The freeze dried fruits samples were crushed and grounded separately with mortar and pestle to form a homogeneous powder. One $\mathrm{g}$ from each sample was added to $10 \mathrm{ml}$ of ice-cold 0.2 M Perchloric acid (HClO4) and subsequently incubated on ice for $1 \mathrm{~h}$. The acid soluble polyamines were then centrifuged at $6000 \mathrm{rpm}$ for $15 \mathrm{~min}$ at $4{ }^{\circ} \mathrm{C}$. Three aliquots of $1 \mathrm{ml}$ from each fruit sample were transferred to microcentrifuge tube and frozen at $-20{ }^{\circ} \mathrm{C}$ until analysis.

\section{High Performance Liquid Chromatography (HPLC) Analysis}

Aliquots of $100 \mu \mathrm{l}$ samples were injected into 1100 Manual injector using mobile phase A (40\% v/v acetonitrile, $60 \% \mathrm{v} / \mathrm{v}$ water) and mobile phase B (100\% acetonitrile). The mobile phases were allowed to run at a flow rate of $1 \mathrm{ml} / \mathrm{min}$ over $27 \mathrm{~min}$ for each sample. Chromatogram was obtained using $347 \mathrm{~nm}$ excitation and $465 \mathrm{~nm}$ emission using fluorescent detector (Agilent 1100 Series). The retention time of polyamines standard was compared with retention time of the samples to allow accurate identification of desired compound.

\section{E. Cell culture}

The A549 cells, a human lung adenocarcinoma cell line, were grown in Dulbecco's Modified Eagle Medium (DMEM) with high glucose and L-glutamine supplemented with $10 \%(\mathrm{v} / \mathrm{v})$ fetal bovine serum (FBS) and $1 \%(\mathrm{v} / \mathrm{v})$ Penicillin-Streptomycin. The cells were grown at $37{ }^{\circ} \mathrm{C}$ in a $\mathrm{CO}_{2}$ incubator until the cells reached $70-80 \%$ cellular confluence. The cells were seeded in $5 \mathrm{~cm}^{2}$ diameter cell culture plates or 96 -well plate at $3.0 \times 10^{5}$ and grown for 48 $\mathrm{h}$ prior treatment.

\section{F. Evaluation of cytotoxicity effect in A549 cells using MTT assay}

The cytotoxicity and proliferation effects of crude plants on A549 cell line were evaluated by MTT assay using the method described by Palmer et al., 2009. Cells were seeded in 96-well plate flat bottom supplied with $5 \% \mathrm{CO}_{2}$ at $37{ }^{\circ} \mathrm{C}$. Following $48 \mathrm{~h}$ of incubation period, the medium was decanted and replaced with selected prophetic fruits treatment solutions in a series of concentrations; $0 \mathrm{mg} / \mathrm{ml}, 10$ $\mathrm{mg} / \mathrm{ml}, 20 \mathrm{mg} / \mathrm{ml}, 30 \mathrm{mg} / \mathrm{ml}, 40 \mathrm{mg} / \mathrm{ml}$ and $50 \mathrm{mg} / \mathrm{ml}$. To analyze cell proliferation rate activity, $10 \mu \mathrm{l}$ of MTT stock solution $(5 \mathrm{mg} / \mathrm{ml})$ in complete PBS was dropped into each well for $4 \mathrm{~h}$ after the treatment period ends. A hundred percent DMSO of $100 \mu \mathrm{l}$ was added to each well to dissolve formazan crystal and absorbance was read at $570 \mathrm{~nm}$ test wavelength and $620 \mathrm{~nm}$ reference wavelength using a microplate reader.

\section{G. Trypan blue exclusion assay}

The number of viable cells and cell viability (\%) following treatment was determined by Trypan blue dye exclusion test. Live cells have intact membranes that exclude any dyes from entering the cells while dead cells take up the blue dye into their cytoplasm. Cells were seeded in $60 \mathrm{~mm}$ plates using 7 time points with $24 \mathrm{~h}$ intervals from $0 \mathrm{~h}$ until $144 \mathrm{~h}$.

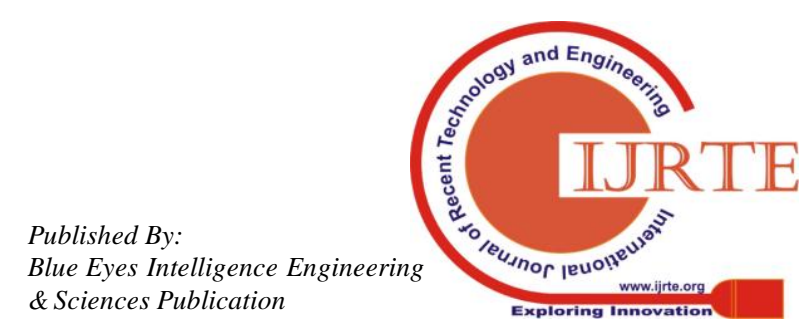


Subsequent $48 \mathrm{~h}$ of attachment period, culture medium was discarded and the monolayer cells were washed with 2 $\mathrm{ml}$ of PBS. Cells were treated with $\mathrm{IC}_{50}$ of the respective fruits prepared with distilled water and culture medium. Every $24 \mathrm{~h}$, the cells were harvested and counted using trypan blue dye and hemocytometer.

\section{H. Quantification of intracellular polyamines in A549 cells}

The remaining harvested cells was used to determine the intracellular polyamine fraction following plant treatment. The cell suspension was centrifuged at $13400 \mathrm{~g}$ for $5 \mathrm{~min}$ and the supernatant was removed. About $1 \mathrm{ml}$ of $0.2 \mathrm{M}$ Perchloric acid was added to the cell pellet and resuspended a few times and mixed well.

The suspension was incubated on ice for $20 \mathrm{~min}$ to extract the acid soluble polyamines. Following incubation time, the cell suspension was centrifuged again at $13400 \mathrm{~g}$ for $5 \mathrm{~min}$ and the supernatant was transferred to a clean microcentrifuge tube and stored at $-20{ }^{\circ} \mathrm{C}$ until analysis using HPLC .

\section{Quantitative Polymerase Chain Reaction (qPCR)}

A549 cells were seeded in $60 \mathrm{~mm}$ plates at 5 time points of treatment; $0 \mathrm{~h}, 6 \mathrm{~h}, 12 \mathrm{~h}, 24 \mathrm{~h}$ and $48 \mathrm{~h}$. The harvested cells then were washed twice with PBS followed by the addition of TRIzol reagent for the extraction of total RNA following the manufacturer's (TRIzol) instructions. The yield and quality of total RNA was measured by absorbance at 260/280 nm. One $\mu \mathrm{g}$ of total RNA and $0.5 \mu \mathrm{g}$ of the random primers were used for reverse transcription following the manufacturer's instructions. The resulting cDNA was diluted to $100 \mu \mathrm{l}$ with Diethylpyrocarbonate treated water and used as a template for real-time PCR. Briefly, PCR primers were designed with a melting temperature $(\mathrm{Tm})$ of $65-95{ }^{\circ} \mathrm{C}$. Amplicon size was 50-150 bases. Forward and reverse primers spanning exon-exon junctions were selected to avoid amplification of genome sequences (for ODC, 5'-AAAACATGGGCGCTTACACT (forward primer) and TGGAATTGCTGCATGAGTTG-3' (reverse primer); for SSAT, 5'- CACCCCTTTTACCACTGCCT (forward primer) and TGCCAATCCACGGGTCATAG -3' (reverse primer); for actin, 5'- AGTCCTGTGGCATCCACGAAA (forward primer) and GTCATACTCCTGCTTGCTGA -3' (reverse primer); for GAPDH, 5'TCCCTGAGCTGAACGGGA AG (forward primer) and GGA GGA GTG GGT GTC GCT GT-3' (reverse primer)). For qPCR analysis, quantitative values were obtained from the threshold cycle value $(\mathrm{Ct})$, which is the point where a significant increase of fluorescence is first detected. The transcript number of rat $\beta$-actin was quantified as an internal RNA control, and each sample was normalized on the basis of its $\beta$-actin content. The relative gene expression level of each sample was then normalized to the control. Final results, expressed as $n$-fold difference in gene expression relative to $\beta$-actin and and calibrator were determined by subtracting the average $\mathrm{Ct}$ value of a target gene from the corresponding $\mathrm{Ct}$ value of the $\beta$-actin gene.

\section{J. Statistical analyses}

All experiments were done in triplicate at least, independently. The results were expressed as mean \pm SD/SEM. Statistical analysis was performed with one-way analysis of variance (ANOVA) followed by the Tukey or Dunnett's multiple comparison post-test using GraphPad Prism software 6.0. The value of $\mathrm{p} \leq 0.05$ was considered as statistically significant.

\section{RESULTS AND FINDINGS}

\section{A. Classification of Polyamines in Selected Medicinal Fruits}

Polyamines are important components of all living cells are maintained by three primary sources: endogenous synthesis, microbial synthesis in the gut and absorption from dietary intake. Diets contribute about 1-2 nmol of putrescine per hour per gram of tissue in the most active organs (Ghani et al., 2015). Thus, reducing dietary polyamines potentially decrease polyamine body pool, hence, decelerates cell proliferation. This strategy, which is known as PDD is an ideal approach alongside current chemotherapy to improve quality of life, pain control, reducing cancer risks and far more important to slow cancer progression. According to the PDD strategy, high polyamine diet is not advisable for high risk populations as it can stimulate extensive cell proliferation and exacerbate cancer conditions. In other countries such as the United Kingdom, Sweden, United States as well as Japan, database of polyamines in local foods has been developed to assess daily dietary intake (Ali et al., 2011). Unfortunately in Malaysia, the database is not yet developed and the existing database may not representative of Malaysian diet. Therefore, to start with, this study aims to provide information about the polyamine content in selected five medicinal fruits as recommended in Al-Qur'an and narrated hadith. Medicinal fruits recommended by Prophet Muhammad were chosen because they are endowed with anti-cancer property as reported by several researchers (Rahmani et al., (2014); Kapadia et al., (2011); Hosyar et al., (2015) and Kountouri et al., 2013).

The total polyamines concentration obtained in each medicinal fruits (Table 1) were used to classify polyamines content into: low $(<100 \mathrm{nmol} / \mathrm{ml})$, intermediate $(101-200$ $\mathrm{nmol} / \mathrm{ml}$ ) and high (> 200nmol/ml) (Cipolla et al., 2007). B. vulgaris (beetroot), P. dactylifera (ajwa dates), V. vinifera (raisins) and F. auriculata (fig) were categorized into low polyamine $(<100 \mathrm{nmol} / \mathrm{ml})$ while $\mathrm{Z}$. jujube was grouped into high polyamine content $(>200 \mathrm{nmol} / \mathrm{ml})$. This finding is consistent with Larque et al., (2007) and Ali et al., (2011) who reported polyamines variation in each food items and between samples respectively. Polyamines content in foods are typically from nanomoles to micromoles per gram with normal adult diets supply several micromoles daily Larque et al., (2007). Cipolla et al.

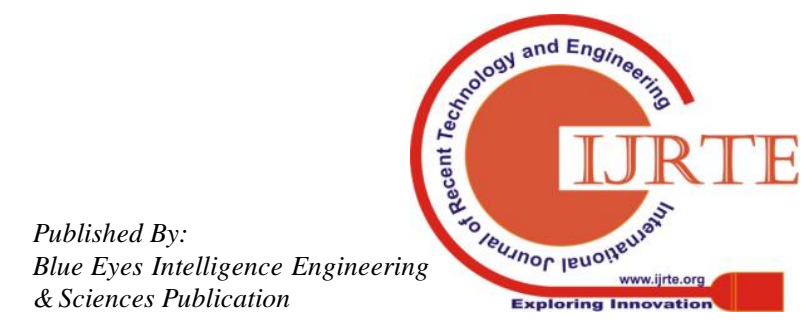


(2007) suggested limiting polyamine diet to low $(<100$ nmoles per $\mathrm{ml})$ or occasionally intermediate $(101-200$ nmoles per $\mathrm{ml}$ ) could reduce 20 -fold exogenous polyamine supply. This is proven by studies in rats that showed dietary polyamine retained in body tissues with $40 \%$ contributed by spermidine followed with putrescine $(10 \%)$ and spermine $(8$ $\%$ ) (Zoumas et al., 2007). It was confirmed that performance and pain controls were improved in hormone refractory prostate cancer patients when polyamine reduced diet was followed accordingly (Cipolla et al., 2003). Interestingly, polyamines deprivation diet improves anti-tumor efficacy of chemotherapy and no enhanced side effects has been observed in these patients. This indicates polyamine deficient diet can be one of ideal approaches to slow cancer and reduces cancer risks.

Table 1 Polyamines content in selected prophetic fruits

\begin{tabular}{|c|c|c|c|c|c|}
\hline \multirow{2}{*}{$\begin{array}{l}\text { Propheti } \\
\text { c Fruits }\end{array}$} & \multicolumn{3}{|c|}{$\begin{array}{c}\text { Polyamines } \\
\text { Concentration } \\
\text { (nmoles/ml) }\end{array}$} & \multirow{2}{*}{$\begin{array}{c}\text { Total } \\
\text { Polyami } \\
\text { nes } \\
\text { Content } \\
\text { (nmoles/ } \\
\text { ml) }\end{array}$} & \multirow{2}{*}{$\begin{array}{c}\text { Classific } \\
\text { ation of } \\
\text { Polyami } \\
\text { nes }\end{array}$} \\
\hline & $\begin{array}{c}\text { Putresci } \\
\text { ne }\end{array}$ & $\begin{array}{l}\text { Spermi } \\
\text { dine }\end{array}$ & $\begin{array}{c}\text { Spermi } \\
\text { ne }\end{array}$ & & \\
\hline $\begin{array}{l}B . \\
\text { vulgaris } \\
\text { (beetroot) }\end{array}$ & $\begin{array}{c}34.0 \pm \\
6.5\end{array}$ & $\begin{array}{c}19.4 \pm \\
3.5\end{array}$ & $\begin{array}{c}1.3 \pm \\
0.3\end{array}$ & $\begin{array}{c}54.7 \pm \\
10.2\end{array}$ & Low \\
\hline $\begin{array}{l}F . \\
\text { auriculat } \\
a \\
\text { (fig) }\end{array}$ & $\begin{array}{c}22.6 \pm \\
2.5\end{array}$ & $\begin{array}{c}14.8 \pm \\
0.4\end{array}$ & $\begin{array}{c}1.9 \pm \\
0.1\end{array}$ & $\begin{array}{c}39.3 \pm \\
3.0\end{array}$ & Low \\
\hline $\begin{array}{l}P . \\
\text { dactylifer } \\
a \\
\text { (ajwa } \\
\text { dates) }\end{array}$ & $\begin{array}{c}5.7 \pm \\
0.5\end{array}$ & $\begin{array}{c}10.7 \pm \\
1.2\end{array}$ & $\begin{array}{c}6.8 \pm \\
1.1\end{array}$ & $\begin{array}{c}23.2 \pm \\
2.8\end{array}$ & Low \\
\hline $\begin{array}{l}V . \\
\text { vinifera } \\
\text { (raisins) }\end{array}$ & $\begin{array}{c}2.8 \pm \\
0.9\end{array}$ & $\begin{array}{c}15.9 \pm \\
1.7\end{array}$ & $\begin{array}{c}9.9 \pm \\
1.5\end{array}$ & $\begin{array}{c}28.6 \pm \\
4.1\end{array}$ & Low \\
\hline $\begin{array}{l}\text { Z. jujube } \\
\text { (jujube) }\end{array}$ & $\begin{array}{c}200.3 \pm \\
3.5\end{array}$ & $\begin{array}{c}16.8 \pm \\
0.7\end{array}$ & $\begin{array}{c}2.5 \pm \\
0.2\end{array}$ & $\begin{array}{c}219.6 \pm \\
4.4\end{array}$ & High \\
\hline
\end{tabular}

\section{B. The cytotoxicity effect of medicinal plants in A549 cells}

Since no documentation on cytotoxicity effect of these medicinal fruits in A549 cells, we evaluated the anti-proliferative activity of selected medicinal fruits using the enzyme-based assay; MTT tetrazolium. Table 2 displays $\mathrm{IC}_{50}$ of respective prophetic fruits. The $\mathrm{IC}_{50}$ was ranged between $15 \mathrm{mg} / \mathrm{ml}$ to $30 \mathrm{mg} / \mathrm{ml}$. B. vulgaris (beetroot) and $Z$. jujube (jujube) exhibited highest (15 $\mathrm{mg} / \mathrm{ml})$ anti-proliferative activity on A549 cells while $V$. vinifera (raisins) exhibited the least anti-proliferative $(30 \mathrm{mg} / \mathrm{ml})$ activity. The fruits B. vulgaris (beetroot) and Z. jujube (jujube) displayed most potent anti-proliferative activity (15 $\mathrm{mg} / \mathrm{ml}$ ) followed by F. auriculata (fig) and P. dactylifera (ajwa dates) $(25 \mathrm{mg} / \mathrm{ml}$ ) and V. vinifera (raisins) (30 $\mathrm{mg} / \mathrm{ml})$. Previous research also proven the cytotoxicity of beetroot against human prostate (PC-3) and breast (MCF-7)(
Kapadia et al. (2011). Lee et al. (2005) concluded anti-cancer potential of beetroot is attributed to betalains, a specific class of antioxidants presents in red beetroot. Other compound that might contribute to this action is hydroxycinnamic which often conjugated with polyamines, offering a tightly regulated intracellular polyamine control (Alcazar et al., 2010). This possibly answers how beetroot induces anti-proliferative activity, by controlling polyamine level through conjugation with the acid.

Anti-proliferative activity of $Z$. jujube has been proven in many scientific studies. Hoshyar et al. (2015) revealed anti-proliferative activity of aqueous extract of $Z$. jujube fruit against breast cancer cell line, MDA-MB-468 is dose and time dependent response which is consistent with our results. Qiao et al. (2014) proposed these effects are the result of triterpenoids compound that present in jujube. Not restricted to breast cancer cell line, jujube inhibited the growth of other cell lines with different $\mathrm{IC}_{50}$ respectively. Lung cancer cells (A549), human hepatoma cells (HepG2), cervical cancer cells (HeLa) and lymphoma cells (U937) were inhibited in response to apoptosis. This is evidenced by Vahedi et al. (2008), who mentioned about Z. jujube caused cell shrinkage and detachment in Hep-2 and HeLa cells, which in agreement with our in vitro assessment on A549 cells. Our observation showed that Z. jujube (jujube) interrupted with cell attachment thereby causing cell death to occur.

Table 2 Summary of $\mathrm{IC}_{50}$ of selected medicinal fruits tested on A549 cell line

\begin{tabular}{lc}
\hline Prophetic Fruits & $\begin{array}{l}\mathbf{I C}_{\mathbf{5 0}} \text { Values } \\
(\mathbf{m g} / \mathbf{m l})\end{array}$ \\
\hline B. vulgaris (beetroot) & $16.1 \pm 0.6$ \\
$Z$. jujube (jujube) & $15.0 \pm 1.0$ \\
F. auriculata (fig) & $25.6 \pm 1.5$ \\
$P$. dactylifera (ajwa dates) & $24.3 \pm 2.7$ \\
V. vinifera (raisins) & $30.2 \pm 2.9$ \\
\hline
\end{tabular}

\section{The Effect of Selected Medicinal Fruits on the A549 Cell Growth}

We also examined the effect of these fruits on A549 cell growth using Trypan blue dye exclusion assay. The cell number reduced significantly following $48 \mathrm{~h}$ of treatments with $\mathrm{IC}_{50}$ of medicinal fruits, suggesting they exhibited growth inhibitory effect against A549 cell line at $48 \mathrm{~h}$ and onwards (Figure 1). Plastina et al. (2012) demonstrated the growth inhibitory effect of $\mathrm{Z}$. jujube was selective to breast cancer cells with no noticeable effect in MCF-10A non-malignant breast epithelial cells and BJ1-hTERT immortalized normal human foreskin fibroblast cells. Hence, we deduced that $\mathrm{Z}$. jujube imparts selective targeting only to cancer cells without attacking surrounding normal cells which then suits normal people to consume as a chemopreventive strategy. 


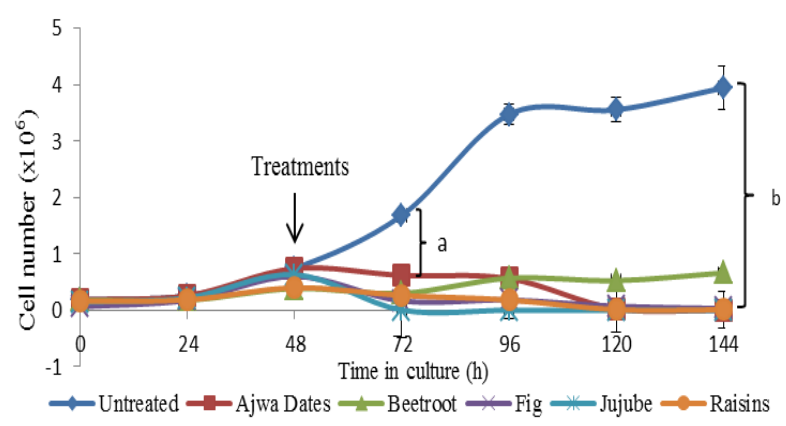

Fig. 1: Growth curve effect following treatment with selected medicinal fruits. A549 cells were seeded at $3 \times 10^{5}$ in $60 \mathrm{~mm}$ plates. Cells were grown for $48 \mathrm{~h}$ prior to exposure to IC50 of fruits. After $48 \mathrm{~h}$ growth plates were harvested at $0 \mathrm{~h}$ and then every $24 \mathrm{~h}$. Cell number was determined. Results are the mean \pm SEM $(n=6)$. Results were analysed statistically using Ordinary Two-way ANOVA with Dunnett's multiple comparison test, (a where $p<0.05, b$ where $\mathrm{p}<0.01$ compare to untreated control)

\section{Intracellular polyamines changes in A549 cells treated with medicinal fruits}

Subsequently, the intracellular polyamines of untreated and treated A549 cells were determined and compared to see the effectiveness of chosen mecicinal fruits in reducing the intracellular polyamine content. It is markedly agreed that subsiding tissue polyamines content is able to reduce cancer growth in humans (Zoumas-morse et al., 2007). There is compelling evidence to suggest depletion of the intracellular polyamine pool can itself be growth inhibitory (Babbar and Gerner, 2011). As shown in Fig. 2, the total intracellular polyamine of untreated A549 was successively increased with time in culture. Conversely, all treated A549 decreased drastically after passing $120 \mathrm{~h}$ in culture. Among three polyamines (putrescine, spermidine and spermine), spermidine and spermine were the largest contributors to the reduction of polyamines in total compared to putrescine following treatments. The probable mechanisms resort to this is due to the involvement of medicinal fruits in polyamine metabolism. Low polyamine intake demonstrated by low polyamine content in prophetic fruits induced inhibition of polyamine synthesis. This is strengthened by a previous discovery by Nakaike et al. who reported administration of PDD enhanced anti-tumor effects of polyamine biosynthesis inhibitors in mice bearing Lewis lung carcinoma (Larque et al., 2007).

Present findings suggested polyamines depletion promoted by selected prophetic fruits can be linked to the anti-proliferative effect. The ability of prophetic fruits to suppress cell proliferation in A549 cells was mediated by the suppression of polyamine synthesis particularly spermidine and spermine. Limited spermidine availability will slow cellular proliferation event, acknowledging its role as the regulator of cellular growth and proliferation. Thus, these results proven that treatment with selected prophetic fruits are able to decrease intracellular polyamines of A549 and alter the concerted polyamine pool in cancer.

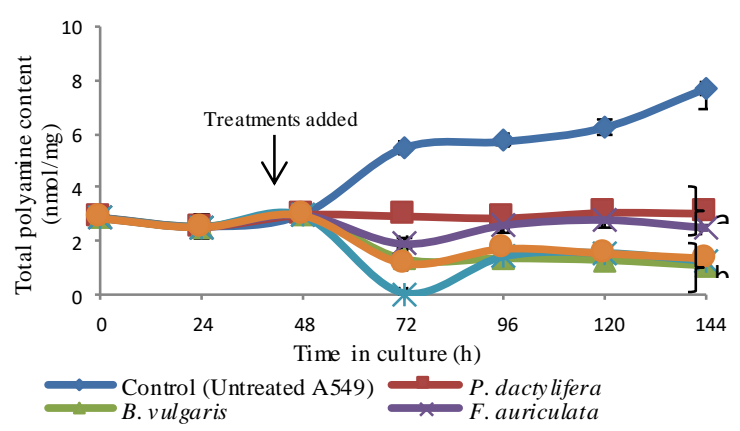

Fig. 2. Intracellular polyamine content following treatment with selected medicinal fruits. A549 cells were seeded at $3 \times 10^{5}$ in $60 \mathrm{~mm}$ plates. Cells were grown for $48 \mathrm{~h}$ prior to exposure to $\mathrm{IC}_{50}$ of prophetic fruits. After $48 \mathrm{~h}$ growth plates were harvested at $0 \mathrm{~h}$ and then every $24 \mathrm{~h}$, with the polyamine fraction extracted in 0.2 M PCA and stored at $-20{ }^{\circ} \mathrm{C}$ until analysis. Samples were then dansylated and the polyamine content was determined using HPLC. Results shown are the mean \pm SEM $(n=3)$. Results were analysed statistically using Ordinary Two-way ANOVA with Dunnett's multiple comparison test $\left({ }^{\mathrm{a}}\right.$ where $\mathrm{p}<0.05 ;{ }^{\mathrm{b}}$ where $\mathrm{p}<0.001$ compared to untreated control).

\section{E. Effect of Medicinal Fruits on Ornithine Decarboxylase (ODC) and Spermidine/Spermine N- Acetyltransferase (SSAT) Gene Expression}

We further extended our investigation on the effect of prophetic fruits on polyamine depletion by evaluating the expression of two critical polyamine metabolic enzymes ODC and SSAT. Ornithine decarboxylase is the first enzyme in polyamine biosynthesis, catalyzes decarboxylation of ornithine into putrescine while SSAT is the key enzyme of polyamine catabolism to ensure polyamine homeostasis is sustains (Ramani et al., 2014). In normal physiological function, the cellular content of ODC and SSAT is tightly controlled in multiple steps of synthesis and degradation. Conversely, they become deregulated in many human cancers including non-small cell lung cancer (NSCLC), making ODC to overexpress (Ancheta et al., 2006) and produce excess polyamines that can be used as biomarkers in hyperplasia diseases (Bachrach, 2004; Linsalata and Russo, 2008). High ODC correlates with good prognosis in NSCLC (Gautschi, 2010). Moreover, decrease in SSAT activity (Linsalata et al., 2006) and increase polyamine uptake is observed in cancer cells as well.

Results have shown that P. dactylifera (ajwa dates), F. auriculata (fig) and Z. jujube (jujube) caused significant decreased of ODC activity but increased when treated with V. vinifera (raisins) (Figure 3). Meanwhile, SSAT activity was up-regulated upon treatment with B. vulgaris (beetroot), F. auriculata (fig) and Z. jujube (jujube) The expression levels of ODC and SSAT was notably changed in several orders of magnitude very quickly in response to the treatment.This is most probably due to their short half-lives (Babbar and Gerner, 2011). 
The downregulation of ODC and upregulation of SSAT as obtained in our results are favorable to reduce intracellular polyamine. This is supported by Seiler and Raul (2005) who reported polyamine can be reduced by modulation of the polyamine metabolic enzymes.

Downregulation of ODC demonstrated by significant reduction in implicated inhibition and catabolism of ODC has taken place (Ramani et al., 2014). Gautschi (2010) proposed low ODC predicts tumor response to ODC inhibition. This is achieved by the binding of ODC monomer to a specific protein, namely antizyme thus render activation of ODC and target it towards proteasome $26 \mathrm{~S}$ for degradation (Ramani et al., 2014). ODC degradation lowered polyamine by impeding putrescine synthesis, likewise inhibition of $26 \mathrm{~S}$ proteasome prevented dexamethasone induce polyamine depletion and apoptosis in thymocytes (Seiler and Raul, 2005). This in turn correlates with previous intracellular polyamine analysis; putrescine decrease in Z. jujube (jujube) treated cells (Figure 2). In contrast, treatment with $\mathrm{V}$. vinifera (raisins) did not raised intracellular polyamine and cell numbers respectively, despite significant upregulation of ODC activity.

This activation of ODC is able to induce apoptosis via overexpression of c-Myc oncogene; a nuclear transcription factor that actively involved in cell cycle control and progression consequently reduces cell number and its polyamine content (Seiler and Raul, 2005). It has been suggested polyamine regulates oncogene expression and functions via transcription and post-transcription processes (Linsalata and Russo, 2008). Apoptosis resulted from ODC activation was seen in murine myeloid cells (Thomas and Thomas, 2001). Further evidences supported that structural homologue of AdoMetDC inhibitor reduced spermidine and spermine content subsequently activates ODC with surplus putrescine and cause apoptosis in few cell lines (Schipper et al., 2000).

In addition to downregulation of ODC, upregulation of SSAT activity has shown to stimulate polyamine catabolism, either initiating acetylation of spermidine and spermine and converts them to spermidine and putrescine by polyamine oxidase or excrete them from the cells (Ramani et al., 2014). It appears that total elimination of spermidine and spermine as we acquired in Figure 3 is the major result of spermidine and spermine degradation and excretion from cells. Moreover, upregulation of SSAT prompts apoptosis owing to the escalation of oxidative stress from accumulation of hydrogen peroxide in polyamine catabolism (Moinard, 2005). This precisely answers the cell number decreased in B. vulgaris (beetroot), F. auriculata (fig) and Z. jujube (jujube) treated cells.

Fig. 3: The effect of selected medicinal fruits on ODC and SSAT activities in A549 cells. (See Appendix - A)

Cells were grown for $48 \mathrm{~h}$ prior to exposure to IC50 of prophetic fruits. After $48 \mathrm{~h}$ growth plates were harvested at 0 $\mathrm{h}$ and then every $6 \mathrm{~h}, 12 \mathrm{~h}, 24 \mathrm{~h}$ and $48 \mathrm{~h}$. Lysates were analyzed as per ODC assay protocol. Results are mean \pm
SEM ( $n=3)$. Results were analysed statistically using Ordinary Two-way ANOVA with Dunnett's multiple comparison test $\left({ }^{\mathrm{a}}\right.$ where $\mathrm{p}<0.05,{ }^{\mathrm{b}}$ where $\mathrm{p}<0.001$ compared to untreated control)

\section{CONCLUSION}

In Malaysia, the therapeutic use of dietary polyamines is still lack of information despite a growing body of evidences on the metabolism of polyamines. The result of our present study showed a proper selection food intake should be taken into consideration among cancer patients and survivor. The high polyamine diet should be avoided in cancer patients and high risk populations to prevent extensive progress of current cancer conditions with regards to the ability of polyamine in promoting cell proliferation. Importantly, as shown in this study, despite potent anti-proliferative effect exhibited by Z. jujube, it is not advisable to be consumed by risky population of cancer due to its high polyamine content. Further screening on polyamine content in well-known anticancer fruits and plants which are available locally is highly warranted in order to improve nutritional cancer therapy as complementary strategy for cancer patients and survivor in Malaysia.

\section{ACKNOWLEDGEMENTS:}

The works described herein have been supported by MyRA Intensive Research Grant Scheme (MIRGS13-01-001-0004), Ministry of Education Malaysia. We would also like to thank Br. Muhammad from Kulliyyah of Pharmacy for assisting in HPLC optimization and Asst. Prof. Dr. Nor Azlina A Rahman for statistical analysis consultation.

\section{REFERENCES}

1. World Health Organization. Cancer fact sheet no. 297. Updated February 2015. Available at http://www.who.int/mediacentre/factsheets/fs297/en/. Accessed: October 2, 2015.

2. World Cancer Report 2014 - WHO - OMS. (n.d.). Retrieved November 17, 2015, from http://apps.who.int/bookorders/anglais/detart1.jsp? codlan=1\&codco $l=76 \& \operatorname{codcch}=31$

3. Steward, W. P., \& Brown, K. (2013). Cancer chemoprevention: a rapidly evolving field. British journal of cancer, 109(1), 1-7

4. Mehta, R. G., Murillo, G., Naithani, R., \& Peng, X. (2010). Cancer chemoprevention by natural products: how far have we come?.Pharmaceutical research, 27(6), 950-961.

5. Milner, J. A. (2008). Nutrition and cancer: essential elements for a roadmap.Cancer letters, 269(2), 189-198

6. Kalač, P. (2009). Recent advances in the research on biological roles of dietary polyamines in man. J Appl Biomed, 7, 65-74

7. Babbar, N., \& Gerner, E. W. (2010). Targeting polyamines and inflammation for cancer prevention. In Clinical Cancer Prevention (pp. 49-64). Springer Berlin Heidelberg

8. Cipolla, B. G., Havouis, R., \& Moulinoux, J. P. (2010). Polyamine reduced diet (PRD) nutrition therapy in hormone refractory prostate cancer patients.Biomedicine \& Pharmacotherapy, 64(5), 363-368.

9. Zagryazhskaya, A., \& Zhivotovsky, B. (2014). miRNAs in lung cancer: A link to aging. Ageing research reviews, 17, 54-67.

10. Sher, T., Dy, G. K., \& Adjei, A. A. (2008, March). Small cell lung cancer. In Mayo Clinic Proceedings (Vol. 83, No. 3, pp. 355-367). Elsevier

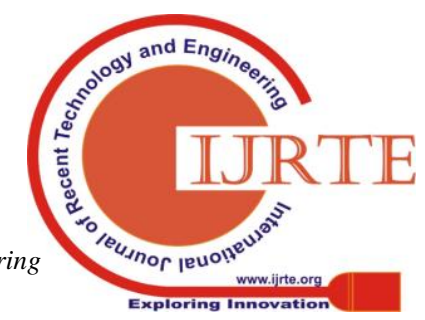


11. Zienolddiny, S., Campa, D., Lind, H., Ryberg, D., Skaug, V., Stangeland, L., ... \& Haugen, A. (2006). Polymorphisms of DNA repair genes and risk of non-small cell lung cancer. Carcinogenesis, 27(3), 560-567.

12. Siegel, R., Naishadham, D., \& Jemal, A.(2012). Cancer statistics, 2012. CA:A Cancer Journal for Clinicians 62(1), 10-29

13. Huang, L., Li, F., Sheng, J., Xia, X., Ma, J., Zhan, M., \& Wong, S. T. (2014). DrugComboRanker: drug combination discovery based on target network analysis. Bioinformatics, 30(12), i228-i236

14. Gerner, E. W., \& Meyskens, F. L. (2004). Polyamines and cancer: old molecules, new understanding. Nature Reviews Cancer, 4(10), 781-792

15. Wallace, HM. (2009). 'The polyamines: past, present and future'. Essays in Biochemistry, vol 46, 1-10

16. Palmer, AJ., Ghani, RA., Kaur, N., Phanstiel, O. \& Wallace, HM (2009). 'A putrescine-anthracene conjugate: a paradigm for selective drug delivery'. Biochemical Journal, vol 424(3),431-438

17. Langner, E., \& Rzeski, W. (2012). Dietary derived compounds in cancer chemoprevention. Wspólczesna Onkologia, 16(5), 394

18. Ghani, RA., Nik Abdul Malek, NN., Yusof, NFM., Jamil, EF.(2015). Ornithine decarboxylase gene expression in human lung adenocarcinoma cells, A549. Jurnal Teknologi, 77(25), 95-99

19. Cipolla, B. G., Havouis, R., \& Moulinoux, J. P. (2007). Polyamine contents in current foods: a basis for polyamine reduced diet and a study of its long term observance and tolerance in prostate carcinoma patients. Amino Acids,33(2), 203-212.

20. Ghani, RA., Jamil, EF., Nor-Azahan Shah, NAM., Nik-Abdul-Malek, NNA.(2015). The role of polyamines in anti-proliferative effect of selected Malaysian herbs in human lung adenocarcinoma cells. Jurnal Teknologi, 77(25), 137-140.

21. Ali, M. A., Poortvliet, E., StrÃkmberg, R., \& Yngve, A. (2011) Polyamines in foods: development of a food database. Food \& nutrition research, 55 .

22. Ramani, D., De Bandt, J. P., \& Cynober, L. (2014). Aliphatic polyamines in physiology and diseases. Clinical Nutrition, 33(1), 14-22.

23. Kapadia, G. J., Azuine, M. A., Rao, G. S., Arai, T., Iida, A., \& Tokuda, H. (2011). Cytotoxic effect of the red beetroot (Beta vulgaris L.) extract compared to doxorubicin (Adriamycin) in the human prostate (PC-3) and breast (MCF-7) cancer cell lines. Anti-Cancer Agents in Medicinal Chemistry (Formerly Current Medicinal Chemistry-Anti-Cancer Agents), 11(3), 280-284

24. Hoshyar, R., Mohaghegh, Z., Torabi, N., \& Abolghasemi, A. (2015) Antitumor activity of aqueous extract of Ziziphus jujube fruit in breas cancer: An in vitro and in vivo study. Asian Pacific Journal of Reproduction,4(2), 116-122

25. Kountouri, A. M., Gioxari, A., Karvela, E., Kaliora, A. C., Karvelas, M., \& Karathanos, V. T. (2013). Chemopreventive properties of raisins originating from Greece in colon cancer cells. Food \& function, 4(3), 366-372

26. Larqué, E., Sabater-Molina, M., \& Zamora, S. (2007). Biological significance of dietary polyamines. Nutrition, 23(1), 87-95

27. Zoumas-morse, C., Rock, C. L., Quintana, E. L., Neuhouser, M. L Gerner, E. W., \& Meyskens, F. L. Jr. (2007). Development of a polyamine database for assessing dietary intake. J Am Diet Assoc. 107 (6), 1024-1027

28. Cipolla, B., Guillé, F., \& Moulinoux, J. P. (2003). Polyamine-reduced diet in metastatic hormone-refractory prostate cancer (HRPC) patients. Biochemical Society Transactions, 31(2), 384-387.

29. Alcázar, R., Altabella, T., Marco, F., Bortolotti, C., Reymond, M. Koncz, C., ... \& Tiburcio, A. F. (2010). Polyamines: molecules with regulatory functions in plant abiotic stress tolerance. Planta, 231(6) 1237-1249.

30. Qiao, A., Wang, Y., Xiang, L., Zhang, Z., \& He, X. (2014). Triterpenoids of sour jujube show pronounced inhibitory effect on human tumor cells and antioxidant activity. Fitoterapia, 98, 137-142

31. Vahedi, F., Najafi, M. F., \& Bozari, K. (2008). Evaluation of inhibitory effect and apoptosis induction of Zyzyphus Jujube on tumor cell lines, an in vitro preliminary study. Cytotechnology, 56(2), 105-111

32. Plastina, P., Bonofiglio, D., Vizza, D., Fazio, A., Rovito, D., Giordano, C.,... \& Gabriele, B. (2012). Identification of bioactive constituents of Ziziphus jujube fruit extracts exerting antiproliferative and apoptotic effects in human breast cancer cells. Journal of ethnopharmacology, 140(2), 325-332.

33. Babbar, N., \& Gerner, E. W. (2010). Targeting polyamines and inflammation for cancer prevention. In Clinical Cancer Prevention (pp. 49-64). Springer Berlin Heidelberg.

34. Linsalata, M., \& Russo, F. (2008). Nutritional factors and polyamine metabolism in colorectal cancer. Nutrition, 24(4), 382-389

35. Gautschi, O. (2010). The polyamine metabolism: renaissance of an old pathway in oncology. Clinical lung cancer, 11(2), 80-81

36. Schipper, R. G., Penning, L. C., \& Verhofstad, A. A. (2000, February). Involvement of polyamines in apoptosis. Facts and controversies: effectors or protectors?. In Seminars in cancer biology (Vol. 10, No. 1, pp. 55-68). Academic Press

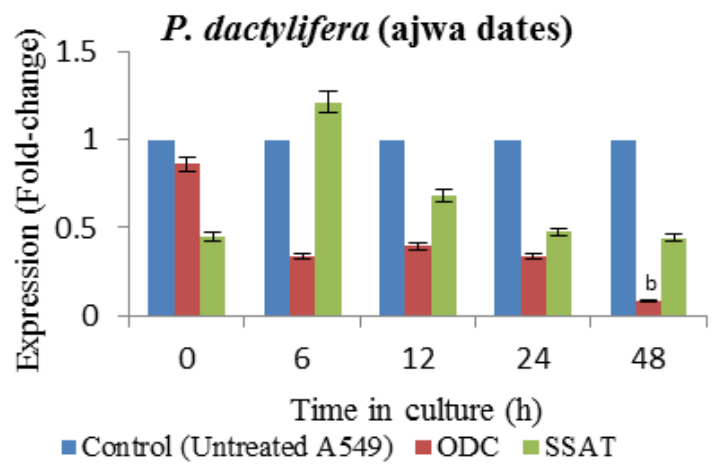

Retrieval Number: C11271083S219/2019@BEIESP

APPENDIX - A

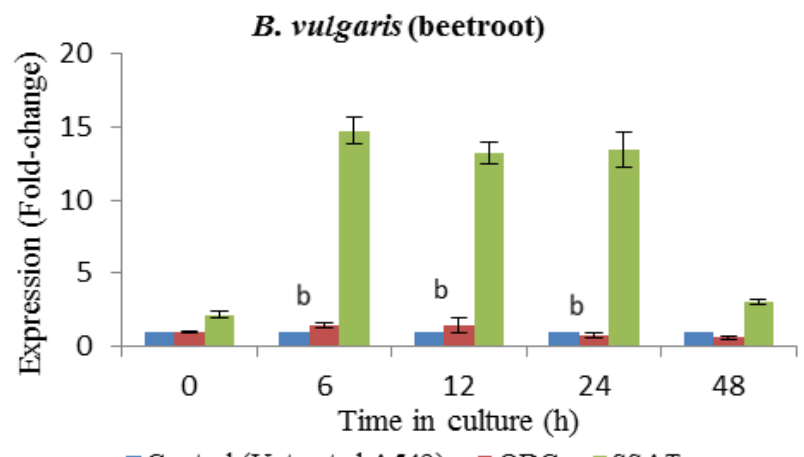

- Control (Untreated A549) $\quad$ ODC $\quad$ SSAT 

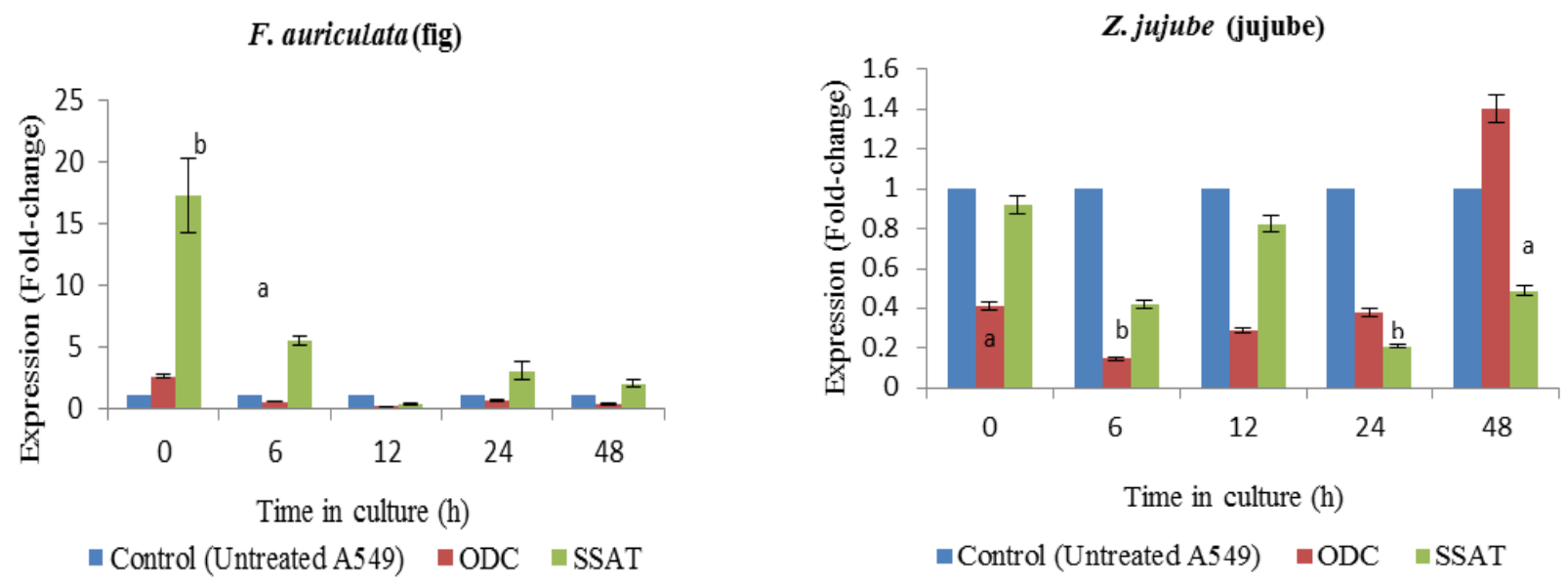

V. vinifera (raisins)

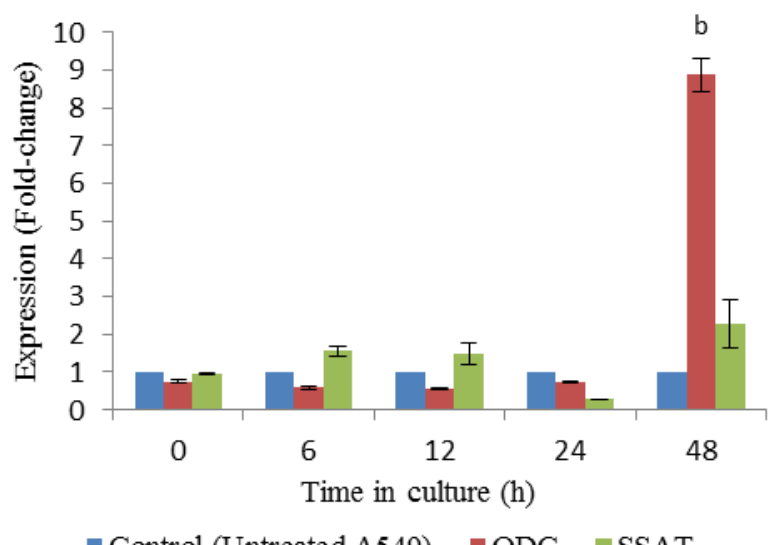

Fig. 3: The effect of selected medicinal fruits on ODC and SSAT activities in A549 cells.

\section{AUTHORS PROFFILE}

My name is Radiah Abdul Ghani, working with Department of Biomedical Science, Kulliyyah of Allied Health Sciences, International Islamic University Malaysia. My area of interest is Biomedical sciences and research. For further details contact me at, radiah@iium.edu.my

My name is Elyna Fatini Jamil, working with currently Department of Biomedical Science, Kulliyyah of Allied Health Sciences, International Islamic University Malaysia. My area of interest is Heath sciences and biomedical.

My name is Muhammad Ibrahim, and currently working with Department of Nutritional Science, Kulliyyah of Allied Health Sciences, International Islamic University Malaysia.my area of interest is Biomedical and health sciences. 